\title{
Genetic characterization and molecular identification of the bloodmeal sources of the potential bluetongue vector Culicoides obsoletus in the Canary Islands, Spain
}

Josué Martínez-de la Puente ${ }^{1 *}$, Javier Martínez ${ }^{2}$, Martina Ferraguti ${ }^{1}$, Antonio Morales-de la Nuez ${ }^{3}$, Noemí Castro ${ }^{3}$ and Jordi Figuerola ${ }^{1}$

\begin{abstract}
Background: Culicoides (Diptera: Ceratopogonidae) biting midges are vectors for a diversity of pathogens including bluetongue virus (BTV) that generate important economic losses. BTV has expanded its range in recent decades, probably due to the expansion of its main vector and the presence of other autochthonous competent vectors. Although the Canary Islands are still free of bluetongue disease (BTD), Spain and Europe have had to face up to a spread of bluetongue with disastrous consequences. Therefore, it is essential to identify the distribution of biting midges and understand their feeding patterns in areas susceptible to BTD. To that end, we captured biting midges on two farms in the Canary Islands (i) to identify the midge species in question and characterize their COI barcoding region and (ii) to ascertain the source of their bloodmeals using molecular tools.

Methods: Biting midges were captured using CDC traps baited with a 4-W blacklight (UV) bulb on Gran Canaria and on Tenerife. Biting midges were quantified and identified according to their wing patterns. A 688 bp segment of the mitochondrial COI gene of 20 biting midges ( 11 from Gran Canaria and 9 from Tenerife) were PCR amplified using the primers LCO1490 and HCO2198. Moreover, after selected all available females showing any rest of blood in their abdomen, a nested-PCR approach was used to amplify a fragment of the COI gene from vertebrate DNA contained in bloodmeals. The origin of bloodmeals was identified by comparison with the nucleotide-nucleotide basic alignment search tool (BLAST).

Results: The morphological identification of 491 female biting midges revealed the presence of a single morphospecies belonging to the Obsoletus group. When sequencing the barcoding region of the 20 females used to check genetic variability, we identified two haplotypes differing in a single base. Comparison analysis using the nucleotide-nucleotide basic alignment search tool (BLAST) showed that both haplotypes belong to Culicoides obsoletus, a potential BTV vector. As well, using molecular tools we identified the feeding sources of 136 biting midges and were able to confirm that C. obsoletus females feed on goats and sheep on both islands.

Conclusions: These results confirm that the feeding pattern of C. obsoletus is a potentially important factor in BTV transmission to susceptible hosts in case of introduction into the archipelago. Consequently, in the Canary Islands it is essential to maintain vigilance of Culicoides-transmitted viruses such as BTV and the novel Schmallenberg virus.
\end{abstract}

Keywords: Bluetongue virus, Bloodmeal, Culicoides, Goats, Schmallenberg virus, Sheep

\footnotetext{
* Correspondence: jmp@ebd.csic.es

'Departamento de Ecología de Humedales, Estación Biológica de Doñana

(EBD-CSIC), C/Américo Vespucio, s/n, Seville E-41092, Spain

Full list of author information is available at the end of the article
} 


\section{Background}

Biting midges of the genus Culicoides Latreille (Diptera: Ceratopogonidae) comprise a highly diverse biological group with more than 1,400 species worldwide [1]. Many biting midge species have ecological [2], economic [3] and sanitary [4] relevance as haematophagous insects and as vectors of pathogens in humans, livestock, poultry and wildlife.

Bluetongue virus (BTV) is one of the most important disease agents transmitted by biting midge Culicoides $[4,5]$. Bluetongue disease (BTD) largely affects ruminants [5], above all in America, Australia, Asia and Africa, and in recent years has expanded into Europe. This spread is probably closely linked to a northward expansion of Culicoides imicola Kieffer, the main Afro-tropical vector species, and the ability of autochthonous Palaearctic Culicoides species to transmit BTV [1]. Among native Culicoides species, C. obsoletus Meigen has been identified as a potential vector of BTV by using different procedures including viral isolation and RT-PCR detection [6,7], as well as experimental infection assays [8]. In addition, this species is thought to have been involved in the outbreaks produced by different BTV serotypes that have occurred in recent years in Europe [9].

The morphological identification of female biting midges to species level is a complex task that usually requires great taxonomic expertise [10]. Their minute size and the huge number of existing biting midge species are two of the main reasons why field studies on Culicoides are laborious and have lagged behind those conducted on other insect vectors [4]. Wing patterns and the morphology of several parts of the body, which usually requires the dissection and separation of the wings, head, abdomen and genitalia, are the main characters employed in species identification [11]. Recently, the morphological identification of biting midges Culicoides has been complemented by the use of molecular tools and as a result more accurate species identification is now possible. In particular, the amplification of a fragment of the mitochondrial cytochrome oxidase subunit I (COI) gene is emerging as a useful and effective tool that can facilitate the identification of Culicoides species [1215] and animals in general [16]. This procedure is especially useful when identifying females of sibling species within species complexes, which are difficult to identify using available morphological information; this is the case for a number of species in the Culicoides obsoletus species complex, which contains both C. obsoletus and C. scoticus Downes \& Kettle.

Located around $100 \mathrm{~km}$ off the African coast, the Canary Islands archipelago (Spain) has one of the highest densities of small ruminants per hectare of agricultural land in the whole of Europe. Although the relationship between ruminant density and the efficient spread of bluetongue is yet to be tested, animal density is thought to play an important role in the spread of this disease [17]. Despite being considered free of BTD [18], it is still important to improve our knowledge of the occurrence of biting midges on these islands. The arrival of the disease in hitherto BTD-free areas could be provoked by the movement of infected livestock or by the passive movement of infected Culicoides on winds, especially over the sea $[19,20]$. Winds transporting sand from the Sahara desert, known locally as calimas (Figure 1a), are habitual in the Canary Islands and potentially transport biting midges from localities in which they are present (see ref. [21]). In addition, C. obsoletus and C. analis Santos Abreu have both been previously reported in the Canary Islands [22]: C. obsoletus has been captured in Tenerife and La Palma [23] and, according to recent information provided by the Spanish National Surveillance Programme, C. obsoletus is present in Fuerteventura and Gran Canaria [18]. The aims of our study were: (i) to identify species and characterize the COI barcoding region of biting midges captured on these islands and (ii) to ascertain the source of bloodmeals from biting midge females using molecular tools that permit the identification of the feeding sources of the bluetongue vector C. obsoletus in the studied areas. We thus captured biting midges from two farms on the Canary Islands, one on Gran Canaria and the other on Tenerife.

\section{Methods}

Biting midges were captured using two CDC-type downdraft miniature suction traps baited with a $4-\mathrm{W}$ blacklight (UV) bulb (model 1212; J.W.Hock, Gainesville, FL) at a distance of $21 \mathrm{~m}$. The light traps were operated from sunset to sunrise for 19 nights from 15/09/2010 to $15 / 12 / 2010$ on the farm of the Universidad de Las Palmas de Gran Canaria (Figure 1b; 28 8'21 N, 1530' 24 W, Arucas, Gran Canaria). During this period, on two nights one trap only was operating at this site. Traps were hung $2.2 \mathrm{~m}$ above ground level and were operated with a UV light. UV light traps are regarded as useful surveillance tools for measuring the relative abundance of midges, although, it is possible that this procedure may not be a reliable indicator of species composition [24]. As well, for four nights from $05 / 12 / 2010$ to $11 / 12$ / 2010, a single trap was placed in the El Pico farm of the Instituto Canario de Investigaciones Agrarias (28 $31^{\prime}$ $24 \mathrm{~N}, 16^{\circ} 22^{\prime} 19 \mathrm{~W}$, Tegueste, Tenerife). All biting midges were preserved in ethanol and maintained at $-80^{\circ} \mathrm{C}$ until further analysis.

All the biting midges collected were quantified and sorted according to their wing patterns [11] using an Olympus SZH stereomicroscope $(10 \times-64 \times$ magnification). Bloodfed females were individually stored for blood-source identification (see below). 

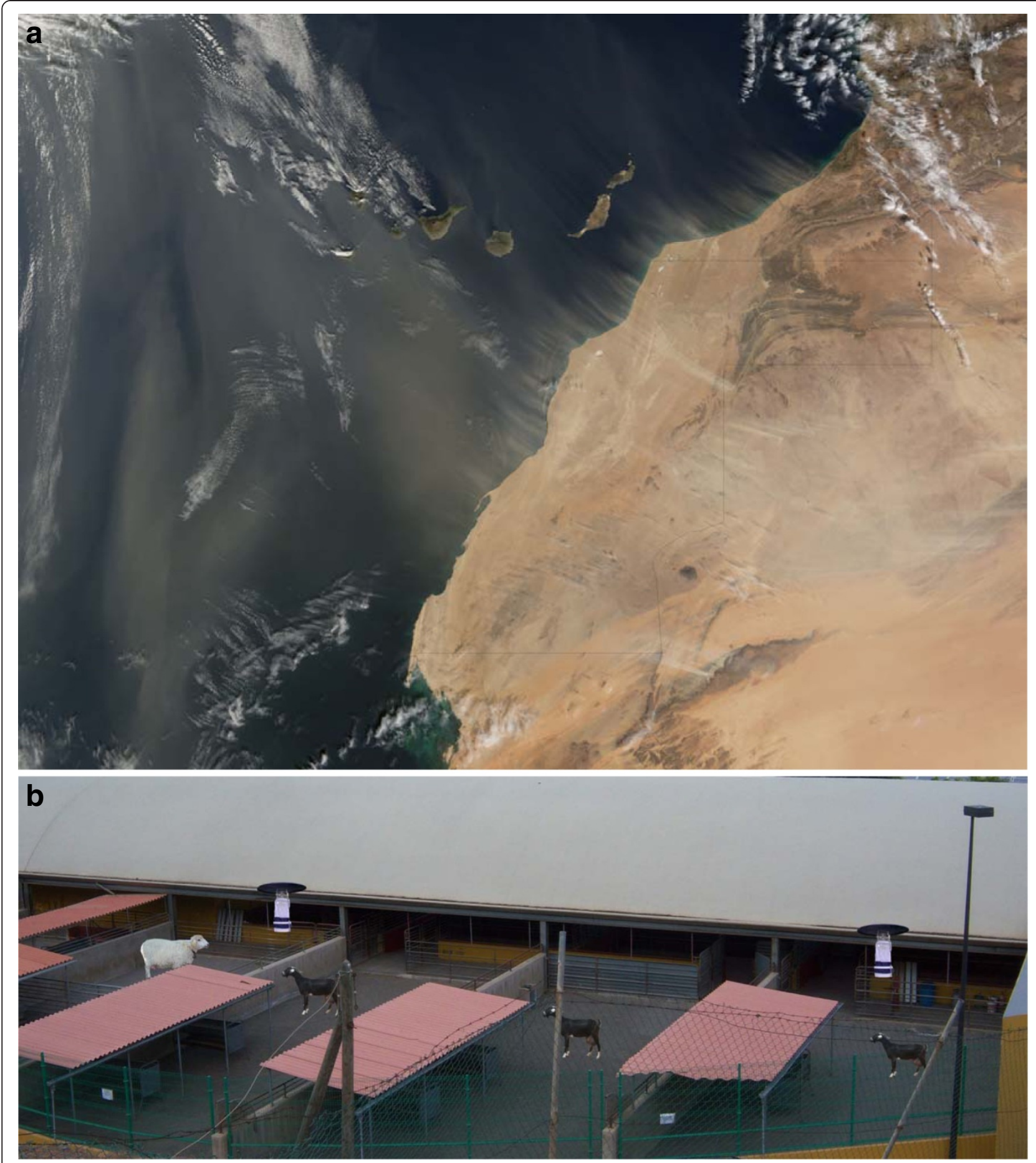

Figure 1 a) Image taken on 20 January 2008 by the Moderate Resolution Imaging Spectroradiometer (MODIS) flying on NASA's Terra satellite showing numerous plumes of dust blowing off the African coast to Canary Islands (accessible at: http://visibleearth.nasa.gov/ view.php?id=19565). b) Location of CDC-type downdraft miniature suction traps and the location of the livestock in the Gran Canaria farm. Note that the number of animals does not correspond with the actual number of animals during the study.

\section{Molecular characterization of biting midges}

Genomic DNA from 20 morphologically identified biting midges (11 from Gran Canaria and nine from Tenerife) was extracted as indicated in ref [2].
A 688 bp segment of the mitochondrial COI gene was PCR amplified from individual biting midges using the primers LCO1490 and HCO2198 ([25], see Table 1). The PCR reaction volume of $20 \mu \mathrm{L}$ consisted of between 20 
Table 1 Primers used in this study to identify biting midges and the sources of their vertebrate bloodmeals

\begin{tabular}{ll}
\hline Primer & Sequence $\left(\mathbf{5}^{\prime}-\boldsymbol{>} \mathbf{3}^{\prime}\right)$ \\
\hline Biting midge identification $^{\text {a }}$ & \\
\hline LCO1490 & GGTCAACAAATCATAAAGATATTGG \\
\hline HCO2198 & TAAACTTCAGGGTGACCAAAAAATCA \\
\hline Vertebrate identification ${ }^{\text {b }}$ & \\
\hline BCFW-M13 & TGTAAAACGACGGCCAGTH- \\
\hline BCRV1 & AAYCAYAARGAYATYGG \\
\hline M13 & GCYCANACYATNCCYATRTA \\
\hline BCRV2 & GTAAAACGACGGCCAGTG \\
\hline
\end{tabular}

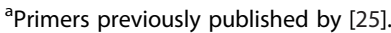

${ }^{b}$ Primers previously published by [26]

and $100 \mathrm{ng}$ DNA template, $50 \mathrm{mM} \mathrm{KCl}, 10 \mathrm{mM}$ Tris$\mathrm{HCl}, 1.5 \mathrm{mM} \mathrm{MgCl}, 0.05 \mathrm{mM}$ of each dNTP, $0.5 \mu \mathrm{M}$ of each primer and $1.25 \mathrm{U}$ of AmpliTaq Gold 360 (Applied Biosystems, Foster City, CA, USA). The reactions were cycled using a Verity thermal cycler (Applied Biosystems) according to the following parameters: $94^{\circ} \mathrm{C}$ for $10 \mathrm{~min}$ (polymerase activation), 40 cycles at $95^{\circ} \mathrm{C}$ for $30 \mathrm{~s}$ (denaturing), $46^{\circ} \mathrm{C}$ for $30 \mathrm{~s}$ (annealing temperature), $72^{\circ} \mathrm{C}$ for $1 \mathrm{~min}$ (extension), and a final extension at $72^{\circ} \mathrm{C}$ for $10 \mathrm{~min}$. Amplicons obtained after PCR assays were recovered from agarose gels, purified using the MoBio kit UltraClean GelSpin and subjected to direct sequencing. DNA fragments obtained were sequenced using an ABI 3130 (Applied Biosystems) automated sequencer.

\section{Bloodmeals identification}

In all, 290 females (74 females from Gran Canaria and 216 from Tenerife) were identified as blood-fed. Using a conservative approach, we included all available females showing any rest of blood in their abdomen to detect the maximum number of potential hosts, thus we included fully engorged and partially engorged females and blood-fed biting midges that, due to the shape and colour of the abdomen, probably contained a partially digested bloodmeal. After excluding some blood-fed females that showed external remains of blood from other damaged blood-fed arthropods, 267 biting midges were processed to identify the origin of their bloodmeals. The abdomen of individual blood-fed biting midges was cut off using sterile tips and introduced into $50 \mu \mathrm{l}$ of lysis solution ( $25 \mathrm{mM} \mathrm{NaOH}, 0.2 \mathrm{mM}$ EDTA), crushed and incubated at $95^{\circ} \mathrm{C}$ for $30 \mathrm{~min}$. At least two negative DNA extraction controls (i.e. absence of tissue) were performed during the PCR experiments. After incubation, the solution was cooled for five minutes, after which time $50 \mu$ l of neutralization solution $(40 \mathrm{mM}$ Tris- $\mathrm{HCl}$ ) was added. Abdomens were simultaneously processed using 96-thermowell plates and stored at $-20^{\circ} \mathrm{C}$ until PCR amplification. Bloodmeal sources were identified using the protocol described and tested in ref. [26] to amplify a fragment of the vertebrate COI gene (Table 1). This method is used to amplify DNA from blood of a diversity of vertebrate species in the abdomen of arthropods including mosquitoes and biting midges [26]. Briefly, this procedure used a nested-PCR approach, using the primary pair of primers M13BCVFW and BCV-RV1 and the nested primer pair M13 and BCV-RV2. Sequences were edited using the software Sequencher v4.9 (Gene Codes, () 1991 - 2009, Ann Arbor, MI) and identified by comparison with the nucleotide-nucleotide basic alignment search tool (BLAST) (GenBank DNA sequence database, National Center for Biotechnology Information) to assign unknown COI sequences to particular vertebrate species. Host species assignment was considered completed when we found a match of $98 \%$ or more between our sequences and those in GenBank.

\section{Results}

A total of 491 biting midge females (201 in Gran Canaria and 290 in Tenerife) and eight males (seven in Gran Canaria and one in Tenerife) were captured during the study. Based on wing patterns, all females were morphologically identified as belonging to the C. obsoletus complex. Amongst the 11 biting midge females from Gran Canaria and nine biting midge females from Tenerife we identified two haplotypes (haplotypes $\mathrm{C} 1$ and $\mathrm{C} 2$ ) that differed only in a single base. With the exception of a single biting midge from Gran Canaria, which was identified as $\mathrm{C} 2$, the rest of the biting midges analysed corresponded to the haplotype $\mathrm{C} 1$. These two haplotypes were unequivocally identified as C. obsoletus by comparison with the GenBank DNA sequence database. Culicoides body parts from three specimens (two $\mathrm{C} 1$ and one $\mathrm{C} 2$ haplotypes) not used in molecular analyses have been deposited in the collection of the Museo Nacional de Ciencias Naturales (MNCN-CSIC), Madrid, Spain (accession numbers: MNCN/ADN 17017, 17018 and 17019). As well, the sequences obtained from these biting midges have been deposited in GenBank [GenBank: JQ740594, GenBank: JQ740595, GenBank: JQ740596].

In all, we obtained positive PCR products from 136 blood-fed females. Biting midges were found to have fed on both goats and sheep in the Canary Islands: specifically, on Gran Canaria, 40 Culicoides females had fed on goats (Capra hircus) and 14 on sheep (Ovis aries), while on Tenerife, 81 females had fed on goats and one on sheep.

\section{Discussion}

Bluetongue has become an important animal health problem in Europe and as a result European legislation now obliges countries susceptible to the presence of 
BTV vectors (those located approximately between parallels $55^{\circ} \mathrm{N}$ and $35^{\circ} \mathrm{S}$ ) to undertake appropriate surveillance programmes that include (i) serological surveillance, (ii) clinical inspection of livestock and (iii) entomological surveillance [18]. Here, we have confirmed (i) the presence of the potential bluetongue vector $C$. obsoletus on two of the islands in the Canary Islands archipelago (Spain) and identified, to our knowledge for the first time, its barcoding region, and have demonstrated (ii) the susceptibility of ruminants (goats and sheep) to the attacks of this biting midge species.

DNA barcoding advocates the adoption of a standard that consists of the identification of a fragment of around $650 \mathrm{bp}$ of the $5^{\prime}$ end of the mitochondrial COI gene of each species [27]. Our results have enabled us to characterise this gene fragment for C. obsoletus, thereby increasing the segment previously amplified and sequenced in several studies of this particular species $[12,13,28]$. Using this approach, we identified two genetic haplotypes of $C$. obsoletus. Haplotype $\mathrm{C} 1$ was present on both islands, Gran Canaria and Tenerife, while haplotype C2 was isolated from a single biting midge captured on Gran Canaria. Our results clearly support the conclusions of previous studies and confirm the utility of molecular tools in the identification of C. obsoletus biting midges to species level [12].

Traditionally, studies of the feeding sources of Culicoides have been conducted using serological techniques [29-33] and only a few have ever investigated this feature by amplification and the sequencing of host DNA [3436]. The cost of PCR amplification and sequencing is high; nevertheless, these tools represent an accurate way of identifying hosts to species level in studies on hostfeeding patterns [37]. However, the efficacy of identification of bloodmeal sources may decrease as the stage of digestion of the host's DNA in the abdomen of the insect increases [38]. In this respect, although we included only females with blood in their abdomen, a proportion probably had a partially digested bloodmeal whose source could not be identified. Moreover, some females may also contain a very low volume of blood, thereby reducing the success of host DNA amplification.

Both birds (mallards and common wood pigeons) and mammals (common rabbits, horses, cattle, sheep and humans) are considered potential hosts of $C$. obsoletus [34-36]. In Europe, the feeding pattern of this biting midge species was previously identified by the amplification of host DNA using mainly species-specific primers $[39,40]$. Our results clearly highlight the importance of ruminants, both goats and sheep, as hosts of C. obsoletus in the Canary Islands, a finding that could be of great importance in the transmission of diseases such as BTD. This may be the case in sheep since clinical symptoms most often manifest themselves in this ruminant [5], even though all ruminants are susceptible to infection with BTV. Further studies on the feeding patterns of this biting midge species in the Canary Islands are necessary in order to identify the susceptibility of other ruminants present in this region to attack by $C$. obsoletus females. Furthermore, the C. obsoletus group has also been found to be involved in the transmission of the newly emergent Schmallenberg virus [41], which affects cattle, goat and sheep production [42]. As well, the direct cost of the insect attacks that cause dermatitis in sheep has a certain veterinary importance [43].

\section{Conclusion}

In sum, our study suggests that all the essential elements needed for an outbreak of BTD are present in the Canary Islands given that $C$. obsoletus has been shown to be one of the main vectors of this viral disease in continental Europe and given the high density of ruminants that are fed on by this midge species on these islands. Thus, the setting up of an active BTD surveillance programme on the Canary Islands is essential and sanitary laws regarding air and sea transport of potentially contaminated insects and livestock must be enforced. Nevertheless, these measures alone will not guarantee that the archipelago will remain free of the disease, since natural wind dispersal of Culicoides midges to the islands could occur $[19,20]$ and as a result some infected midges could arrive from Africa.

\section{Competing interests}

The authors declare that they have no conflicting interests.

\section{Authors' contributions}

Conceived and designed the experiments: JMP JM NC JF. Contributed reagents/materials/analysis tools: JMP JM MF AMN NC JF. All authors have read and approved the final manuscript.

\section{Acknowledgements}

This study was partially funded by projects CGL2009-09439, CGL2009-11445 and AGL2009-11944 from the Spanish Ministry of Science and Innovation and co-financed by European Regional Development Funds. Also, this study was partially funded by EU grant FP7-261504 EDENext and is catalogued by the EDENext Steering Committee as EDENext051 (http://www.edenext.eu)

The contents of this publication are the sole responsibility of the authors and don't necessarily reflect the views of the European Commission. Josué Martínez-de la Puente is currently supported by a contract from the programme Junta para la Ampliación de Estudios (CSIC) co-financed by Fondo Social Europeo. Martina Ferraguti is not currently supported by any grant. Santiago Merino kindly lent us the CDC traps. We would like to thank Joaquín Muñoz and Isabel Martín for their help in the laboratory and Anastasio Argüello, Lorenzo Enrique Hernández-Castellano and Isabel Moreno-Indias for their help in insects collection. Isabel Rey and Beatriz Álvarez kindly provided us with the accession numbers for samples deposited at the collection of MNCN. Finally, we acknowledge support of the publication fee by the CSIC Open Access Publication Support Initiative through its Unit of Information Resources for Research (URICI).

\section{Author details}

${ }^{1}$ Departamento de Ecología de Humedales, Estación Biológica de Doñana (EBD-CSIC), C/Américo Vespucio, s/n, Seville E-41092, Spain. ²Departamento de Microbiología y Parasitología, Facultad de Farmacia, Universidad de Alcalá, 
Alcalá de Henares, Madrid E-28871, Spain. ${ }^{3}$ Department of Animal Science, Universidad de las Palmas de Gran Canaria, Arucas E-35413, Spain.

Received: 17 March 2012 Accepted: 24 July 2012

Published: 24 July 2012

\section{References}

1. Purse BV, Mellor PS, Rogers DJ, Samuel AR, Mertens PPC, Baylis M: Climate change and the recent emergence of bluetongue in Europe. Nat Rev Microbiol 2005, 3:171-181.

2. Martínez-de la Puente J, Martínez J, Rivero-de Aguilar J, Herrero J, Merino S: On the specificity of avian blood parasites: revealing specific and generalist relationships between haemosporidians and biting midges. Mol Ecol 2011, 20:3275-3287.

3. Velthuis AGJ, Saatkamp HW, Mourits MCM, de Koeijer AA, Elbers ARW: Financial consequences of the Dutch bluetongue serotype 8 epidemics of 2006 and 2007. Prev Vet Med 2010, 93:294-304.

4. Mellor PS, Boorman J, Baylis M: Culicoides biting midges: their role as arbovirus vectors. Annu Rev Entomol 2000, 45:307-340.

5. Sperlova A, Zendulkova D: Bluetongue: a review. Vet Med 2011, 56:430-452.

6. de Liberato C, Scavia G, Lorenzetti R, Scaramozzino P, Amaddeo D, Cardeti G, Scicluna M, Ferrari G, Autorino GL: Identification of Culicoides obsoletus (Diptera: Ceratopogonidae) as a vector of bluetongue virus in central Italy. Vet Rec 2005, 156:301-304

7. Mehlhorn H, Walldorf V, Klimpel S, Jahn B, Jaeger F, Eschweiler J, Hoffmann B, Beer M: First occurrence of Culicoides obsoletus-transmitted Bluetongue virus epidemic in Central Europe. Parasitol Res 2007, 101:219-228.

8. Carpenter S, Lunt HL, Arav D, Venter GJ, Mellor PS: Oral susceptibility to bluetongue virus of Culicoides (Diptera: Ceratopogonidae) from the United Kingdom. J Med Entomol 2006, 43:73-78.

9. Saegerman C, Berkvens D, Mellor PS: Bluetongue epidemiology in the European Union. Emerg Infect Dis 2008, 14:539-544.

10. Goffredo M, Meiswinkel R: Entomological surveillance of bluetongue in Italy: methods of capture, catch analysis and identification of Culicoides biting midges. Vet ltal 2004, 40:260-265.

11. Delécolle JC: Nouvelle contribution à l'étude systématique et iconographique des espèces du genre Culicoides (Diptera: Ceratopogonidae) du Nord-Est de la France. PhD thesis. Université Louis Pasteur de Strasbourg, 'Vie et Terre'. 1985.

12. Pagés N, Sarto i Monteys V: Differentiation of Culicoides obsoletus and Culicoides scoticus (Diptera: Ceratopogonidae) based on mitochondrial cytochrome oxidase subunit I. J Med Entomol 2005, 42:1026-1034.

13. Nolan DV, Carpenter S, Barber J, Mellor PS, Dallas JF, Mordue (Luntz) AJ, Piertney SB: Rapid diagnostic PCR assays for members of the Culicoides obsoletus and Culicoides pulicaris species complexes, implicated vectors of bluetongue virus in Europe. Vet Microbiol 2007, 124:82-94.

14. Muñoz-Muñoz F, Talavera S, Pagès N: Geometric morphometrics of the wing in the subgenus Culicoides (Diptera: Ceratopogonidae): from practical implications to evolutionary interpretations. J Med Entomol 2011 48:129-139.

15. Lassen SB, Nielsen SA, Skovgård H, Kristensen M: Molecular differentiation of Culicoides biting midges (Diptera: Ceratopogonidae) from the subgenus Culicoides Latreille in Denmark. Parasitol Res 2012, 110:1765-1771.

16. Hebert PDN, Cywinska A, Ball SL, deWaard JR: Biological identifications through DNA barcodes. Proc Biol Sci 2003, 270:313-321.

17. EFSA Panel on Animal Health and Welfare: Scientific Opinion on Bluetongue monitoring and surveillance. EFSA Journal 2011, 9:2192. doi:10.2903/j.efsa.2011.2192

18. http://rasve.mapa.es/Publica/InformacionGeneral/Enfermedades/ enfermedades.asp.

19. Alba A, Casal J, Domingo M: Possible introduction of bluetongue into the Balearic Islands, Spain, in 2000, via air streams. Vet Rec 2004, 155:460-461.

20. Ducheyne E, de Deken R, Bécu S, Codina B, Nomikou K, Mangana-Vougiaki O, Georgiev G, Purse BV, Hendickx G: Quantifying the wind dispersal of Culicoides species in Greece and Bulgaria. Geospat Health 2007 1:177-189.

21. Baylis M, el Hasnaoui H, Bouayoune H, Touti J, Mellor PS: The spatial and seasonal distribution of African horse sickness and its potential Culicoides vectors in Morocco. Med Vet Entomol 1997, 11:203-212.
22. Delécolle JC: Ceratopogonidae. In Catálogo de los Diptera de España, Portugal y Andorra (Insecta). Edited by Carles-Tolrá Hjorth-Andersen M. Spain. Monografias S.E.A 2002, 8:26-33.

23. Izquierdo I, Martín JL, Zurita N, Arechavaleta M (Eds): Lista de especies silvestres de Canarias (hongos, plantas y animales terrestres. Spain: Consejería de Medio Ambiente y Ordenación Territorial, Gobierno de Canarias; 2004

24. Carpenter S, Mellor PS, Torr SJ: Control techniques for Culicoides biting midges and their application in the U.K. and northwestern Palaearctic. Med Vet Entomol 2008, 22:175-187.

25. Folmer O, Black M, Hoeh W, Lutz R, Vrijenhoek R: DNA primers for amplification of mitochondrial cytochrome $\mathrm{c}$ oxidase subunit I from diverse metazoan invertebrates. Mol Mar Biol Biotechnol 1994 3:294-297.

26. Alcaide M, Rico C, Ruiz S, Soriguer R, Muñoz J, Figuerola J: Disentangling vector-borne transmission networks: a universal DNA barcoding method to identify vertebrate hosts from arthropod bloodmeals. PLoS One 2009, 4(9):e7092

27. Hajibabaei M, Singer GAC, Hebert PDN, Hickey DA: DNA barcoding: how it complements taxonomy, molecular phylogenetics and population genetics. Trends Genet 2007, 23:167-172.

28. Augot D, Sauvage F, Jouet D, Simpha E, Veuille M, Couloux A, Kaltenbach ML, Depaquit J: Discrimination of Culicoides obsoletus and Culicoides scoticus, potential bluetongue vectors, by morphometrical and mitochondrial cytochrome oxidase subunit I analysis. Infect Genet Evol 2010, 10:629-637.

29. Braverman Y, Boreham PFL, Galum R: The origin of blood meals of female Culicoides pallidipennis trapped in a sheepfold in Israel. J Med Entomol 1971, 8:379-381.

30. Walker AR, Boreham PFL: Blood feeding of Culicoides (Diptera, Ceratopogonidae) in Kenya in relation to the epidemiology of bluetongue and ephemeral fever. Bull Entomol Res 1976, 66:181-188.

31. Mullens BA, Dada CE: Insects feeding on desert bighorn sheep, domestic rabbits, and japanese quail in the Santa Rosa Mountains of Southern California. J Wildl Dis 1992, 28:476-480.

32. Blackwell A, Mordue (Luntz) AJM, Mordue W: Identification of bloodmeals of the Scottish biting midge, Culicoides impunctatus, by indirect enzyme-linked immunosorbent assay (ELISA). Med Vet Entomol 1994, 8:20-24

33. Mullens BA, Gerry AC, Sarto i Monteys V, Pinna M, González A: Field studies on Culicoides (Diptera: Ceratopogonidae) activity and response to deltamethrin applications to sheep in Northeastern Spain. J Med Entomol 2010, 47:106-110

34. Lassen SB, Nielsen SA, Skovgård H, Kristensen M: Molecular identification of bloodmeals from biting midges (Diptera: Ceratopogonidae: Culicoides Latreille) in Denmark. Parasitol Res 2011, 108:823-829.

35. Ninio C, Augot D, Delécolle JC, Dufour B, Depaquit J: Contribution to the knowledge of Culicoides (Diptera: Ceratopogonidae) host preferences in France. Parasitol Res 2010, 108:657-663.

36. Santiago-Alarcon D, Havelka P, Schaefer HM, Segelbacher G: Bloodmeal analysis reveals avian Plasmodium infections and broad host preferences of Culicoides (Diptera: Ceratopogonidae) vectors. PLoS One 2012, 7:e31098

37. Gómez-Díaz E, Figuerola J: New perspectives in tracing vector-borne interaction networks. Trends Parasitol 2010, 26:470-476.

38. Haouas N, Pesson B, Boudabous R, Dedet JP, Babba H, Ravel C: Development of a molecular tool for the identification of Leishmania reservoir hosts by blood meal analysis in the insect vectors. Am J Trop Med Hyg 2007, 77:1054-1059.

39. Bartsch S, Bauer B, Wiemann A, Clausen P-H, Steuber S: Feeding patterns of biting midges of the Culicoides obsoletus and Culicoides pulicaris groups on selected farms in Brandenburg, Germany. Parasitol Res 2009, 105:373-380.

40. Garros C, Gardès L, Allène X, Rakotoarivony I, Viennet E, Rossi S, Balenghien T: Adaptation of a species-specific multiplex PCR assay for the identification of blood meal source in Culicoides (Ceratopogonidae: Diptera): applications on Palaearctic biting midge species, vectors of Orbiviruses. Infect Genet Evol 2011, 11:1103-1110.

41. Rasmussen LD, Kristensen B, Kirkeby C, Rasmussen TB, Belsham GJ, Bødker R, Bøtner A: Culicoids as vectors of Schmallenberg virus [letter]. Emerg Infect Dis 2012. doi:10.3201/eid1807.120385. in press. 
42. Lievaart-Peterson $\mathrm{K}$, Luttikholt SJM, Van den Brom R, Vellema P: Schmallenberg virus infection in small ruminants - First review of the situation and prospects in Northern Europe. Small Rumin Res 2012. doi:10.1016/j.smallrumres.2012.03.006. in press.

43. Yeruham J, Perl S, Braverman Y: Seasonal allergic dermatitis in sheep associated with Ctenocephalides and Culicoides bites. Vet Dermatol 2004 15:377-380

doi:10.1186/1756-3305-5-147

Cite this article as: Martínez-de la Puente et al:: Genetic characterization and molecular identification of the bloodmeal sources of the potential bluetongue vector Culicoides obsoletus in the Canary Islands, Spain.

Parasites \& Vectors 2012 5:147.

\section{Submit your next manuscript to BioMed Central and take full advantage of:}

- Convenient online submission

- Thorough peer review

- No space constraints or color figure charges

- Immediate publication on acceptance

- Inclusion in PubMed, CAS, Scopus and Google Scholar

- Research which is freely available for redistribution 